\title{
Bis(3-methylsalicylato)bis(picolinamide)copper(II) complex - preparation, spectral properties and supposed structure
}

\author{
Simona Matejováa ${ }^{a}$, Miroslava Puchoňováa , Dominika Hrindováa, \\ Vladimír Jorík ${ }^{\mathrm{a}}$, Milan Mazúr ${ }^{\mathrm{b}}$, Dušan Valigura ${ }^{\mathrm{c}}$ \\ ${ }^{a}$ Department of Inorganic Chemistry, Faculty of Chemical and Food Technology, \\ Slovak University of Technology, Radlinského 9, 812 37, Bratislava, Slovakia \\ ${ }^{b}$ Department of Physical Chemistry, Faculty of Chemical and Food Technology, \\ Slovak University of Technology, Radlinského 9, 812 37, Bratislava, Slovakia \\ 'Department of Chemistry, University of SS Cyril and Methodius in Trnava, \\ J. Herdu 2, 91701 Trnava, Slovakia \\ miroslava.puchonova@stuba.sk
}

\begin{abstract}
Blue methylsalicylatocopper(II) complex with picolinamide $\mathrm{Cu}(3-\mathrm{Mesal})_{2}(\mathrm{pnia})_{2}$ has been prepared and characterized by elemental analysis and spectral methods. Based on the infrared spectra, monodentate coordination of 3-methylsalicylate anion has been assumed and the coordination variability of the anion has been shown. By determination and refinement of the unit cell from powder diffraction data, the existence of a monomeric $\mathrm{Cu}$ (II) complex can be anticipated. EPR spectrum of the complex is in good agreement with these results. The $g$-factors fulfil the relation $g_{||}>g_{\perp}>2.0023$, which is consistent with the $\mathrm{d}_{\mathrm{x}^{2}}-\mathrm{y}^{2}$ ground electronic state and indicates coordination sphere of distorted tetragonal symmetry $\left\{\mathrm{CuN}_{2} \mathrm{O}_{2} \mathrm{O}_{2}\right\}$ for the central copper(II) ions.
\end{abstract}

Keywords: picolinamide, powder diffraction analysis, copper(II) complex, spectral properties, EPR spectroscopy

\section{Introduction}

Superoxide dismutase (SOD) is a copper containing enzyme present in most living systems which catalyzes dismutation of the superoxide anion. When the catalytical function of the enzyme is disturbed, various disorders can occur in the biosystem. Therefore, the preparation of low molecular weight analogues mimicking the SOD enzyme function has great potential in medicine. In previous studies, copper(II) complexes with nicotinamide (nia) derivatives have been examinated for many reasons e.g. their biological aspects (antiinflammatory, antibacterial, SOD mimetic activities) and of course for their magnetic or structural properties (Zvimba, 2007; Puchoňová, 2018; Shiekl, 2018). Information concerning the complex structure is important for understanding the interaction between molecules in a solution as well as in pure substance solid state and moreover in cocrystal formation. Different intermolecular interactions can lead to the formation of various supramolecular architectures which leads to variable structure modifications. It is well known that hydrogen bonds formation plays a significant role, therefore, these coordination compounds are interesting for solid state chemistry and bioinorganic chemistry (Moncol, 2008; Repická,
2010). Currently, nia derivatives like picolinamide (pnia) or isonicotinamide (inia) provide several structure motifs especially in this field of various carboxylatocopper(II) complexes. So, the final product formation and coordination mode of bonded ligands are influenced by the positional isomers of nicotinamide (Fig. 1.).

The most frequent coordination mode of nia and inia is monodentate by nitrogen atom of the pyridine ring (Özbek, 2017; Bozkurt, 2013, Köse, 2011, Hökelek, 2010). Only a few complexes containing these ligands are coordinated in the bridging mode where oxygen atom of the carboxamide group is bonded to the neighbouring central atom (Perec, 2011; Kozlevčar, 1999; Moncol, 2007). On the other hand, the picolinamide molecule (pria) is dominantly coordinated only in the chelating bonding mode by the pyridine ring nitrogen atom and by the carboxamide group oxygen atom (Sieron, 2004). Only several examples of carboxylatocopper(II) complexes with pnia can be found in literature (Dačič, 2013).

Our attention has focused on the preparation of novel biologically (SOD) active copper(II) compounds with picolinamide and on their characterization. A new coordination compoud of the composition $\mathrm{Cu}(3-\mathrm{Mesal})_{2}(\text { pnia })_{2}$, its chemical and physical properties, are presented. Possible structural motif 
<smiles>NC(=O)c1ccccn1</smiles>

a) pnia<smiles>NC(=O)c1cccnc1</smiles>

b) nia<smiles>NC(=O)c1ccncc1</smiles>

c) inia

Fig. 1. Positional isomers of nicotinamide.

of the prepared complex and its purity were studied by elemental analysis (EA), powder diffraction analysis (XRPD), electronic absorption spectra (UV/Vis), infrared spectra (IR) and Electron Paramagnetic Resonance spectroscopy (EPR).

Coordination variability of the studied compoud $\mathrm{Cu}(3-\mathrm{Mesal})_{2}(\text { pnia })_{2}$ was compared with that of previously published $\left[\mathrm{Cu}(3-\mathrm{Mesal})_{2}(\mathrm{inia})_{2}\right]_{2}$, $\left[\mathrm{Cu}(3-\mathrm{Mesal})_{2}(\text { nia })_{2}\right]$ complexes (Puchoňová, 2018; Puchoňová, 2015).

\section{Experimental}

\section{Synthesis}

Analytical grade (Sigma, USA or Acros Organics, USA) chemicals and solvents were used without further purification. Picolinamide (pnia) was washed down with a necessary amount of solvent (water or acetonitrile) into the aqueous solution of copper(II) acetate. Then, 3-methylsalicylic acid was added to the reaction mixture. The precipitate was filtered off and the mother liquid was left for crystallization. The product was characterized by available methods as elemental analysis, infrared spectra and powder X-ray diffraction.

Anal Calc for $\mathrm{Cu}(3-\mathrm{Mesal})_{2}(\mathrm{pnia})_{2}$ : C, 55.1; H, 4.3; N, 9.2. Found: C, 54.6; H, 4.4; N, 9.1.

\section{Apparatus and physical measurement}

Analyses of carbon, hydrogen and nitrogen were carried out on a CHNSO FlashEATM 1112 Automatic Elemental Analyzer. Infrared spectrum $\left(4000-400 \mathrm{~cm}^{-1}\right)$ of the complex was measured on a NICOLET 5700 FT-IR spectrophotometer at room temperature using the ATR technique. Electronic spectrum (190-1100 nm) of the compound was measured in a Nujol suspension using a SPECORD 250 Plus spectrophotometer at room temperature.

The first derivative Cu(II) EPR spectrum of polycrystalline copper(II) complex was recorded on an X-band ( $\approx 9.4 \mathrm{GHz})$ EMX EPR spectrometer (Bruker, Germany) at room temperature. The spin Hamiltonian parameter values were obtained from the experimental EPR spectra using WinEPR (Thiele, 1992) and then they were further refined by computer simulation using SimFonia (Weber, 1995).

X-ray powder diffraction analysis was carried out on a parafocusing Bragg Brentano diffractometer Philips PW1820 using CoK $\alpha$ radiation $(40 \mathrm{kV}$, $35 \mathrm{~mA}$ ) equipped with an automatic divergence slit and a curved graphite monochromator placed in the diffracted beam. The polycrystalline sample was measured in Si zero-background sample holder in the $2 \ominus$ range of $3-60^{\circ}$, step size of $0.02^{\circ}$ and the counting time of $1 \mathrm{~s}$ per step at room temperature. The structures were drawn using Mercury 2.0. (Macrae, 2008)

\section{Result and discussion}

A change of the reaction conditions (stoichiometric ratio $=\mathrm{Cu}:$ pnia $: 3 \mathrm{MesalH}$ or solvent) led to the formation of a new complex of the composition $\mathrm{Cu}(3-\mathrm{Mesal})_{2}$ (pnia $)_{2}$ which was found based on EA. The blue product was formed in the stoichiometry of $1: 2: 2$ in water. The prepared complex absorbed at $632 \mathrm{~nm}$; this broad asymmetric ligand field band attributes to the $d \leftarrow d$ transition maxima which corresponds to its blue colour. There are also intraligand bands (250-300 $\mathrm{nm}$ ) and charge transfer bands in the range of $300-350 \mathrm{~nm}$.

Infrared spectrum of $\mathrm{Cu}(3-\mathrm{Mesal})_{2}$ (pnia) ${ }_{2}$ comprises bands confirming the presence of all characteristic functional groups. The spectrum contains characteristic of a broad envelope of probably two or three overlapping medium intensity bands with their maxima in the region from 3250 to $3500 \mathrm{~cm}^{-1}$ assignable to $\mathrm{OH}$ stretches and two medium intensity band assignable to $\mathrm{NH}$ vibration at about $3180 \mathrm{~cm}^{-1}$ and $3305 \mathrm{~cm}^{-1}$. The bands corresponding to $\nu_{\mathrm{as}}\left(\mathrm{COO}^{-}\right)$ and $\nu_{\mathrm{s}}\left(\mathrm{COO}^{-}\right)$are at $1602 \mathrm{~cm}^{-1}$ and $1394 \mathrm{~cm}^{-1}$. Differences between antisymmetric and symmetric stretch $\left(\Delta \nu=\nu_{\mathrm{as}}-\nu_{\mathrm{s}}\right)$ are greater than $\Delta \nu$ for the ionic form. The $\Delta \nu$ value for the complex is consistent with the monodentate mode of the carboxylate group (Nakamoto, 2009). 


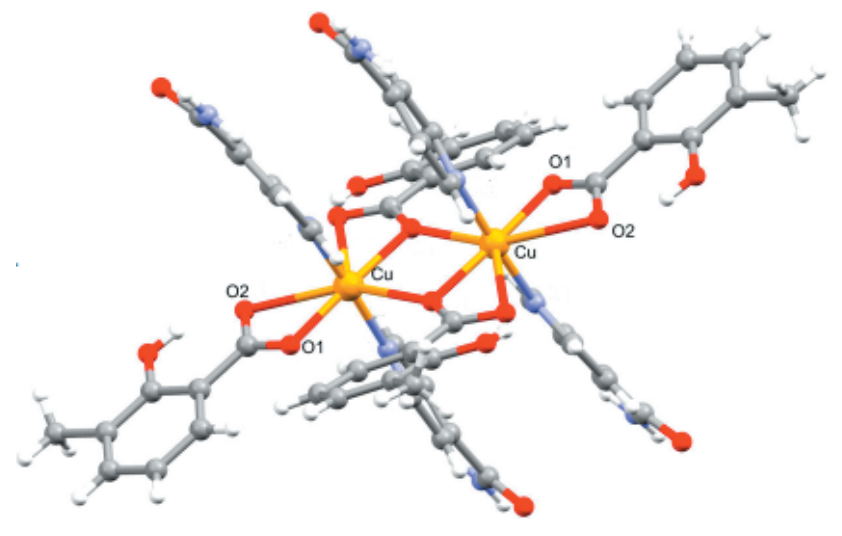

a) $\left[\mathrm{Cu}(3-\mathrm{Mesal})_{2}(\text { inia })_{2}\right]_{2}$

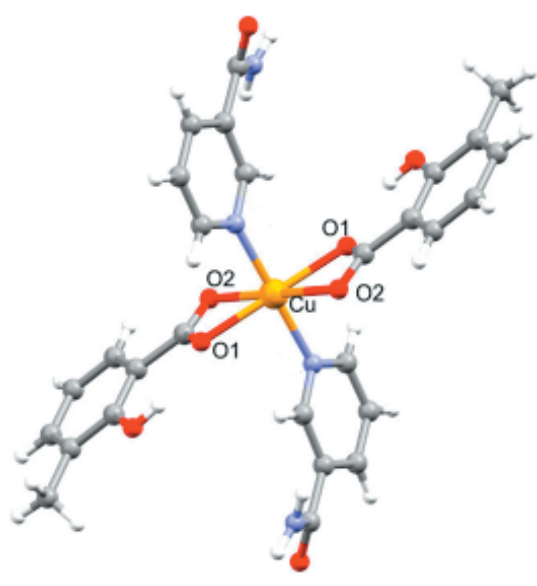

b) $\left[\mathrm{Cu}(3-\mathrm{Mesal})_{2}(\text { nia })_{2}\right]$

Fig. 2. Molecular structure of complexes (Puchoňová, 2018; Puchoňová, 2015).

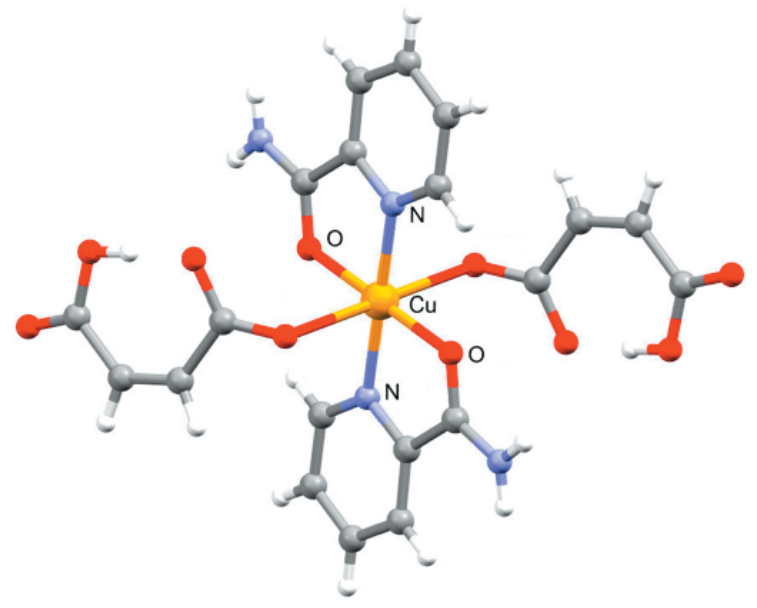

Fig. 3. Molecular structure of complex $\left[\mathrm{Cu}(\mathrm{mal})_{2}(\mathrm{pnia})_{2}\right]$ (Sieron, 2007).

Literature data provide some evidence of 3-methylsalicylate variability of coordination modes which are shown in Fig. 2 (Puchoňová, 2018; Puchoňová, 2015) as well as a difference of the anion coordination mode in relation to the nicotinamide derivatives. Bidentate chelating mode is preferred in monomeric $\left[\mathrm{Cu}(3-\mathrm{Mesal})_{2}(\mathrm{nia})_{2}\right]$ and bidentate chelating together with bridging mode were found in the dimeric $\left[\mathrm{Cu}(3-\mathrm{Mesal})_{2}(\text { inia })_{2}\right]_{2}$ complex. According to data from the Cambridge Structural Database, the length of $\mathrm{Cu}-\mathrm{O}$ bond in methylsalicylate copper(II) complexes is in the range of 1.94$2.03 \AA$ for chelating or monodentate mode, and 1.92-2.06 $\AA$ (Cu-O1 shorter bond) 2.35-2.78 (Cu-O2 longer bond) for bidentate chelating mode (CSD version 5.40 updates November 2018; Groom, 2016). For the presented compound, $\mathrm{Cu}(3$ Mesal $)_{2}(\text { pnia })_{2}$, monodentate bonding mode has been suggested from the anion spectral data.

Moreover, the absence of $\mathrm{C}=\mathrm{O}$ vibration in the IR spectrum of $\mathrm{Cu}(3-\mathrm{Mesal})_{2}(\text { pnia })_{2}$ at about $1690 \mathrm{~cm}^{-1}$ allows us to suppose that oxygen atom of the pnia carboxamide group is bonded to the central atom (Bakiler, 2007). Literature and crystallographic database provide additional examples where the picolinamide molecule is bonded in the bidentate chelating mode by nitrogen atom of the pyridine ring and oxygen atom of the carboxamide group to central atom. One of them is carboxylatocopper(II) complex $\left[\mathrm{Cu}(\mathrm{mal})_{2}(\text { pnia })_{2}\right]$ where mal is monoanion of maleic acid (Fig. 3) (Sieron, 2007). In this type of copper(II) complexes, the length of $\mathrm{Cu}-\mathrm{O}$ bond is in the range of $1.94-2.38 \AA$, and that of $\mathrm{Cu}-\mathrm{N}$ is $1.96-2.00 \AA$. If derivatives of nicotinamide are joined to copper atom only by nitrogen atom, the distance of $\mathrm{Cu}-\mathrm{N}$ is in the range of $1.94-2.38 \AA$ (CSD version 5.40 updates November 2018; Groom, 2016).

EPR spectrum of the polycrystalline complex $\mathrm{Cu}(3-$ Mesal $)_{2}(\text { pnia })_{2}$ measured at room temperature is shown in Figure 4. The corresponding computed EPR spectrum is indicated by the red line. An axially symmetric Cu(II) EPR spectrum with unresolved hyperfine splitting was obtained. Additionally, the EPR 


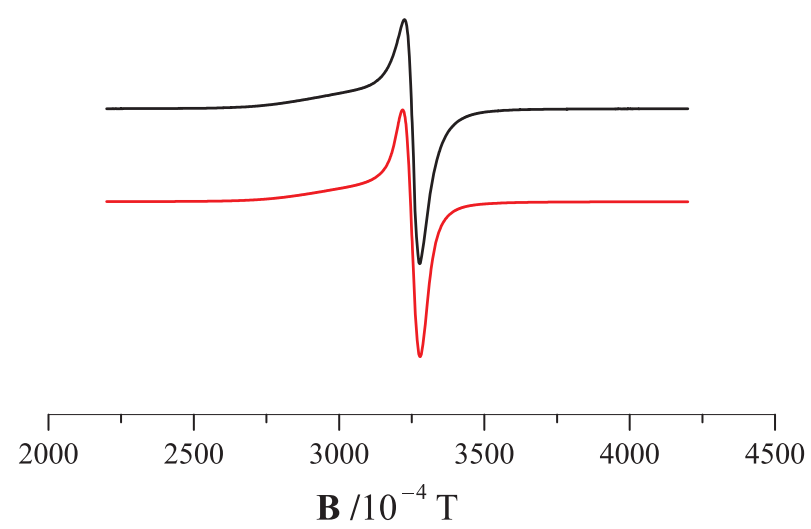

Fig. 4. Experimental (black line) and simulated (red line) EPR spectra of copper(II) complex recorded at room temperature.

spectrum of this copper(II) complex was measured in a wide sweep width of $800 \mathrm{mT}$. However, no typical EPR resonance due to the presence of copper(II) dimeric complex was observed.

The spin Hamiltonian parameters evaluated from the experimental $\mathrm{Cu}$ (II) EPR spectrum and further refined by computer simulation are $g_{||}=2.267 \pm 0.002$, $g_{\perp}=2.078 \pm 0.002$. The $g$-factor values of the axially symmetric Cu(II) EPR spectra fulfilled the usual relation of $g_{||}>g_{\perp}>2.0023$, which is consisted with the $\mathrm{d}_{\mathrm{x}^{2}-\mathrm{y}^{2}}$ ground electronic state and indicates distorted tetragonal symmetry of coordination spheres for copper(II) central atoms.

Finally, the geometric parameter $G=\left(g_{||}-2\right) /\left(g_{\perp}-2\right)$ was calculated. The $G$-value is 3.423 and the relation of $G<4$ indicates the presence of exchange interaction between the copper(II) ions (Hathaway, 1970a; Hathaway,1970b). The above presented $g$-factor values are in good accordance with those for similar monomeric copper(II) complexes reported in literature (Hathaway,1970a; Hathaway,1970b; Goodman, 1970; Halaška, 2016; Öztürk, 2012).

When single crystals with suitable size and good stability are not available, powder diffraction analysis (XRPD) is an appropriate method for structure determination. In such situations, a high quality powder pattern should be recorded. However, in this case, XRPD was used only to verify the phase purity of the sample and to determine the lattice parameters. Profile fitting and ab initio indexing of powder diffraction patterns collected for the presented complex with pnia were done using the multipurpose program CMPR (Toby, 2005) with incorporated autoindexing program DICVOL06 (Boultif, 2004). The best solution is the triclinic crystallographic system with the figure of merit being $\mathrm{M}(20)=22.5$ and the following unit cell parameters: $a=7.1734(34) \AA, b=7.1855(53) \AA$, $c=14.9808(66) \AA, \alpha=83.249(43)^{\circ}, \beta=78.227(38)^{\circ}$, $\gamma=61.305(53)^{\circ}$. Subsequently, the obtained unit cell parameters were refined with the Le Bail method using program Jana2006 (Petříček, 2014), where correction of the powder profile (Legendre polynomials with 25 terms for calculation, Pseudo-Voigt peak-shape function, asymmetry by Berar-Baldinozzi correction) was performed. The refined unit cell parameters are: $a=7.1753(15) \AA$,

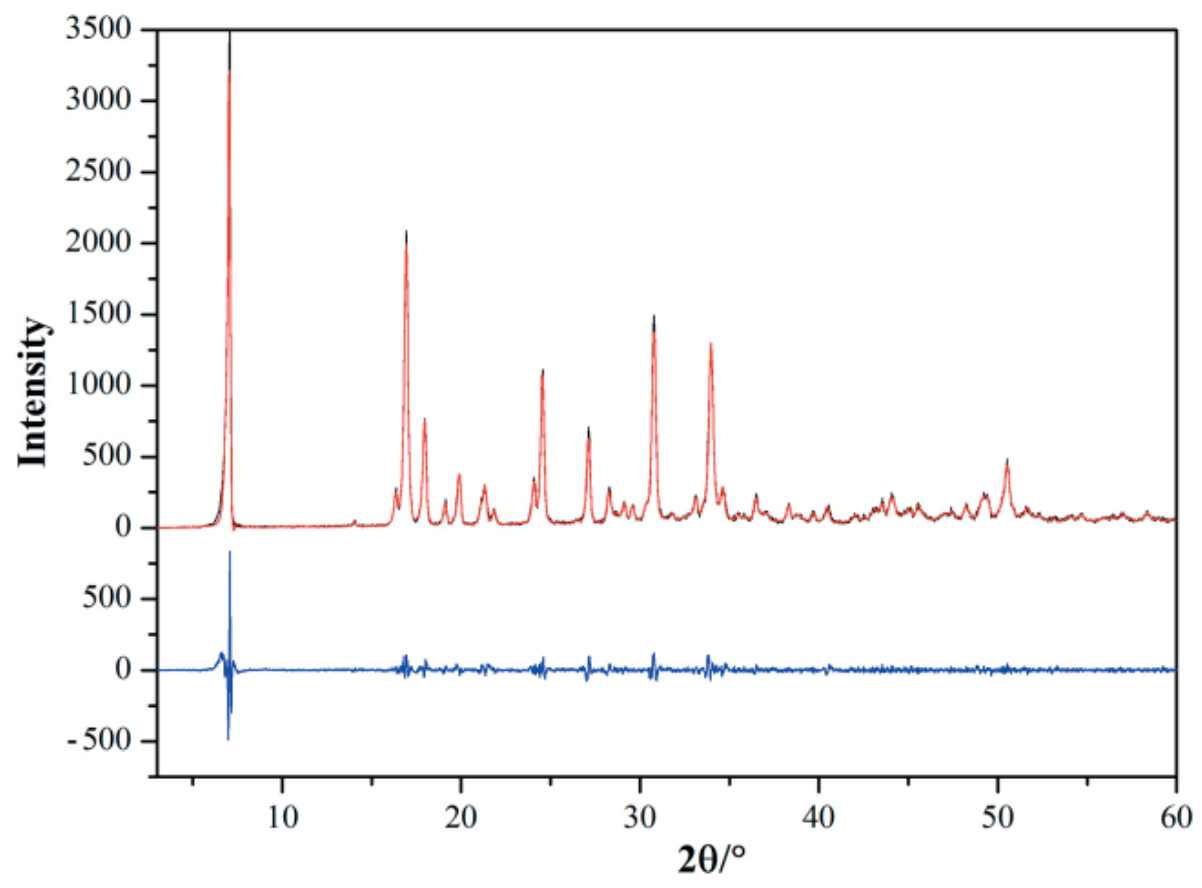

Fig. 5. Final Le Bail fit: measured data (black line), calculated data (red line) and difference curve (blue line) as a function of absolute diffracted intensity at the diffraction angle of $2 \theta$. 
Tab. 1. Comparison of unit cell volumes and crystal densities of Cu(II) complexes.

\begin{tabular}{|c|c|c|c|c|}
\hline Chemical formula & Molecular formula & $Z$ & $\begin{array}{c}V \\
\left(\AA^{3}\right)\end{array}$ & $\begin{array}{l}\text { Crystal density } \\
\qquad\left(\mathrm{g} \mathrm{cm}^{-3}\right)\end{array}$ \\
\hline$\left[\mathrm{Cu}(3-\mathrm{Mesal})_{2}(\text { inia })_{2}\right]_{2}$ & $2\left(\mathrm{C}_{28} \mathrm{H}_{26} \mathrm{CuN}_{4} \mathrm{O}_{8}\right)$ & 1 & $1345.56(14)$ & $1.5058(2)$ \\
\hline$\left[\mathrm{Cu}(3-\mathrm{Mesal})_{2}(\mathrm{nia})_{2}\right]$ & $\mathrm{C}_{28} \mathrm{H}_{26} \mathrm{CuN}_{4} \mathrm{O}_{8}$ & 4 & $2836.86(17)$ & $1.4284(2)$ \\
\hline $\mathrm{Cu}(3-\mathrm{Mesal})_{2}(\text { pnia })_{2}$ & $\mathrm{C}_{28} \mathrm{H}_{26} \mathrm{CuN}_{4} \mathrm{O}_{8}$ & 1 & $664.4(2)$ & $1.5247(3)$ \\
\hline
\end{tabular}

*all samples were measured at the room temperature

$b=7.1863(9) \AA, c=15.0034(22) \AA, \alpha=83.219(13)^{\circ}$, $\beta=78.286(16)^{\circ}, \gamma=61.328(17)^{\circ}$ and $V=664.4(2) \AA^{3}$. As shown in Fig. 5, the polycrystalline sample of $\mathrm{Cu}(3-\mathrm{Mesal})_{2}(\text { pnia })_{2}$ does not contain any impurities.

Based on the volume of the unit cell from JANA2006 $\left(\mathrm{V}=664.4(2) \AA^{3}\right)$ in comparison to densities and volumes considering number of formula units $Z$ of previously solved crystal structures of complexes $\left[\mathrm{Cu}(3 \text {-Mesal })_{2}(\text { inia })_{2}\right]_{2}$ and $\left[\mathrm{Cu}(3-\mathrm{Mesal})_{2}(\text { nia })_{2}\right]$ (Table 1$)$. We can claim that possible molecular structure of the complex is monomeric with the given chemical formula, which is in good agreement with the conclusion from EPR and infrared spectroscopy. Experimental errors for crystal densities of $\left[\mathrm{Cu}(3-\text { Mesal })_{2}(\text { inia })_{2}\right]_{2}$ and $\left[\mathrm{Cu}(3-\mathrm{Mesal})_{2}(\mathrm{nia})_{2}\right]$ were evaluated using the standard analysis errors (Taylor, 1997).

\section{Conclusion}

In conclusion, a new $\mathrm{Cu}(3-\mathrm{Mesal})_{2}(\text { pnia })_{2}$ complex was prepared and characterized by available methods (EA, UV/Vis, IR, EPR and XPRD). The polycrystalline complex EPR spectrum recorded at room temperature gave the g-factor values of $g_{||}>g_{\perp}>2.0023$, which is consistent with the $d_{x^{2}-y^{2}}$ ground electronic state and indicates the coordination sphere of distorted tetragonal symmetry for central copper(II) ions. Based on infrared spectroscopy, we can suggest a monodentate bonding mode of the carboxylate group of 3-methylsalicylate and bidentate chelating mode of picolinamide can be proposed. The possibility of monomeric unit presence in this complex structure has been found from X-ray powder diffraction analysis, which was used only to verify the phase purity of the sample and to determine the lattice parameters of $\mathrm{Cu}(3-\mathrm{Mesal})_{2}(\text { pnia })_{2}$. However, collection of high quality powder diffraction data or growing of suitaible single crystal is necessary for structure determination. Up to today, any salicylatocopper(II) complex with pnia has not been found in the Cambridge Structural Database nor in literature. Therefore, the subsequent reaserch will be related to the synthesis of other methylsalicylatocopper(II) complexes with pnia and the study of their SOD mimetic activity which could be potencially used in medicine

\section{Acknowledgement}

This work was supported by courtesy of the Slovak Grant Agency (VEGA 1/0686/17, VEGA 1/0639/18) and by the Slovak Research and Development Agency under the contact No. APVV-15-0053. MM thanks the Ministry of Education, Science, Research and Sport of the Slovak Republic for funding within the scheme "Excellent research teams".

\section{References}

Bakiler M, Blukbasi O, Yilmaz A (2007) J. Mol. Struct. 826: 6 .

Boultif A, Louer D (2004) J. Appl. Crystallogr. 37(5): 724. Bozkurt N, Dilek N, Caylak Delibas N, Necefoglu H, Hökelek T, Saka G, Tercan B, Cimen E, Necefoglu H (2013) Acta Crystallogr. Sect. E: Struct. Rep. Online 69: m356.

Goodman BA, Raynor JB (1970) Adv. Inorg. Chem. Radiochem. 13: 135.

Groom CR, Bruno IJ, Lightfoot MP, Ward SC (2016) Acta Cryst. B72: 171.

Hathaway BJ, Tomlinson AAG (1970a) Coord. Chem. Rev. 5: 1.

Hathaway BJ, Billing DE (1970b) Coord. Chem. Rev. 5: 43.

Halaška J, Čechová D, Lawson MK, Růzičková Z, Jorík V, Koman M, Valko M, Kozlevčar B, Moncol J (2016) Chem. Papers 70: 101.

Hökelek T, Saka G, Tercan B, Cimen E, Necefoglu H (2010) Acta Crystallogr. Sect. E: Struct. Rep. Online 66: m955.

Kozlevčar B, Leban I, Turel I, Segedin P, Petric M, Pohleven F, White AJP, Williams DJ, Sieler J (1999) Polyhedron 18: 755.

Köse DA, Necefoglu H, Sahin O, Buyukgungor O (2011) J. Chem. Cryst. 41: 297.

Macrae CF, Bruno IJ, Chisholm JA, Edgington PR, McCabe P, Pidcock E, Rodriguez-Monge L, Taylor R, van de Streek J, Wood PA (2008)J. Appl. Cryst. 41: 466.

Moncol J, Maroszova J, Koman M, Melnik M, Valko M, Mazur M, Lis T (2008) J. Coord. Chem. 61: 3740.

Moncol J, Mudra M, Lonnecke P, Hewitt M, Valko M, Morris H, Svorec J, Melnik M, Mazúr M, Koman M (2007) Inorg. Chim. Acta 360: 3213.

Nakamoto K (2009) Infrared and Raman spectra of inorganic and coordination compounds, Part B, John Wiley\&Sons, Inc, 118. 
Özbek FE, Sertcelik M, Yuksek M, Necefoglu H, Celik RC, Nayir GY, Hökelek T (2017) J. Mol. Struct. 1150: 112 .

Öztürk F, Bulut A, Paşaoglu H, Bulut I, Büyükgüngör O (2012) Spect. Chim. Acta: Part A: 97: 24.

Petřičček V, Dušek, M, Palatinus L (2014) Z. Kristallogr. Cryst. 229(5): 345.

Puchoňová M, Matejová S, Jorík V, Šalitroš I, Švorc L, Mazúr M, Moncol J, Valigura D (2018) Polyhedron 151: 152.

Puchoňová M, Repická Z, Moncol J, Růžičková Z, Mazúr M, Valigura D (2015) J. Mol. Struct. 1092: 1.

Repická Z, Moncol J, Puchoňová M, Jorík V, Mikloš D, Lis T, Padělková Z, Mazúr M, Valigura D (2010) Struct. Chem. 21(5): 1093.

Shiekh RA, Said MA, Malik MA, Hashmi AA (2018) Trop. J. Pharm. Research. 17 (5): 865.
Sieron L (2004) Acta Crystallogr. Sect. E: Struct. Rep. Online 60: m297.

Sieron L (2007) Acta Crystallogr. Sect. E: Struct. Rep. Online 63: $\mathrm{m} 862$.

Taylor JR (1997) An introduction to error analysis. Sausalito, Calif: University Science Books.

Thiele H, Etstling J, Such P, Hoefe P (1992) WINEPR, Bruker Analytic Gmb, Germany.

Toby BH (2005) J. Appl. Crystallogr. 38(6): 1040.

Valigura D, Moncol J, Korabik M, Pučeková Z, Lis T, Mrozinski J, Melník M (2006) Eur. J. Inorg. Chem. 3813.

Zvimba JN, Jackson GE (2007) J. Inorg. Biochem. 101: 148.

Weber RT (1995) WINEPR SimFonia, EPR Division, Bruker Instr. Inc., Billerica, USA. 